planetary Radar", 11 pages, seem too condensed. The next paper with the ambitious title "Present Day Techniques in Radio Astronomy", 9 pages, consists only of some general comments. Nevertheless, the papers in this book are sufficiently comprehensive to give an outline of varied aspects of radio astronomy and a focal point for further reading.

The organizers have rightly included an optical astronomer to describe problems of the identification of radio sources, and mathematical experts to discuss theoretical implications, cosmological theories and observational tests. Radio methods have opened a most important field of astronomical research adding a new vista to the optical picture. Progress in astronomy demands the fullest integration of theory with all observational data. The book should prove helpful not only to students of radio astronomy but also to optical and theoretical astronomers.

The rate of progress in research tends to put the title of the book in a precarious position. The conference was held in 1962 and in one or two respects it is already evident that 'to-day' was 'yesterday'. A fow postscripts added in proof bear evidence of this. Since the book was prepared there have been several further advances, for example, the measurements of the polarization of the extra-galactic radio sources, the theory of energy release by gravitational implosion, the observation of radio flare stars, radar echoes from Mars and Mercury, and so on. It is not an uncommon experience for the writer of a radioastronomical survey to find that significant items of discovery have appeared between the completion of his manuscript and its publication or soon afterwards. This is inevitable and does not seriously detract from its value. It is in fact because of this high rate of advance, and the unwieldy mass of contributions to scientific journals, that it is essential to have the type of résumé provided by this book to enable one to see the subject in proper perspective and to endeavour to keep abreast with progress and developments. The University of Manchester and Jodrell Bank staff are to be congratulated on a praiseworthy effort in organizing the Summer School and making available to all this useful record of the course. J. S. Hey

\section{A MODERN SCEPTICAL CHYMIST}

\section{Essays on Nucleic Acids}

By Dr. Erwin Chargaff. Pp. xii + 211. (Amsterdam and London: Elsevier Publishing Company, 1963.) $45 s$.

$\mathrm{M}$ OST scientific treatises can be read without violent emotional reactions on the part of the reader, but no one can look through the pages of this book without a strong feeling of irritation, anger or even cynical approval.

Few molecular biologists, for example, will learn with equanimity that the scientific territory which they cover is "the practice of biochemistry without a licence". But Dr. Chargaff enjoys trailing his coat in the most provocative fashion and in this book of essays he takes full advantage of his opportunities.

Most of the material is not new and is, in fact, the reprinting of nine articles and lectures which have been published elsewhere between 1950 and 1961. They include his well-known Harvey Lecture of 1956 and his inaugural address to the fourth International Congress of Biochemistry in Vienna in 1958. They are all, of course, written in Dr. Chargaff's own inimitable and pungent style with a wealth of scholarly reference to the works of the classical philosophers of which few modern scientists are capable. The author's use of words is magnificent-it is sobering to reflect that he could probably have written with equal facility in more than one European language.

The theme of the whole book is, of course, deoxyribonucleic acid, "the philosopher's stone of our days, the quintessence of contemporary alchemy", but Dr. Chargafi looks at it through the critical eyes of the sceptical chemist who has handled it for more than twenty years rather than through the starry eyes of the more credulous biologist. His own contributions to the subject have, of course. been substantial and have not always received full recognition. How many people, for example, recollect that it was he who paved the way for modern views on base pairing by his pioneer observation published in 1950 that ". . . in all deoxypentose nucleic acids examined thus far the molar ratios . . . of adenine to thymine and of guanine to cytosine were not far from 1"? These early observations are reproduced in Chapter 1 and the subject is further developed in subsequent chapters dealing mainly with the relative proportions of bases in INA's of all kinds, work which sounded the death knell of the now almost forgotten tetranucleotide hypothesis.

Later chapters are concerned with what is almost certainly the most important outstanding problem in nucleic acid chemistry-the determination of the sequence of bases along the polynucleotide chain. The problem is still unsolved, but Dr. Chargaff's own contributions to this exceedingly difficult question are pre-eminent.

The last two chapters aro what tho author calls a "divertimento". One is the unedited and unexpurgated version of a lecture given in a much abbreviated form at a conference in 1962. The other is an imaginary conversation between an Old Chemist and a Young Molecular Biologist. (If biochemistry is accepted to be the study at the molecular and atomic level of the organization and function of biological systems, What then is molecular biology?). The two part without having resolved theil. differences, but their rather acrimonious discussion gives Dr. Chargaff the opportunity to castigate those trends in modern scientific development which he so cordially detests - the appearance of dogmas in biological thinking and what he terms the "motorized anthropomorphism that disfigures much of our biological reasoning at present".

His withering criticisms go, of course, too far, but there is no better antidote to that tendeney to uncritical cornplacency which so readily distorts one's sense of values in this field. Dr. Chargaff may be what he himself calls an angry old man and his eomments will not be popular. especially with the younger generation of scientists, but it is precisely by them that his book should be read and reflected on.

J. N. Davinson

\section{WATERPROOFING AND WATER-REPELLENCY}

Waterproofing and Water-Repellency

Edited by Dr. J. L. Moilliet. Pp. x+502. (Amsterdam and London: Elsevier Publishing Company, 1963.) $100 \mathrm{~s}$.

$7 \mathrm{HE}$ editor of a book consisting of contributions from

a number of specialists in different, but related, fields has a difficult task, and it must be admitted that Dr. Moilliet's efforts have resulted in the production of a most useful and readable volume. Nevertheless, the inherent defects of co-operative authorship have not been entirely eliminated, and it would have been better if all aspects of textile waterproofing, with the possible exception of testing, could have been dealt with by a single writer. This would have ensured uniformity of style and treatment and, more important, a systematic comparison between the merits of differont types of agent might have been attempted. The chapters on non-textile aspects of water-repellency are, however, essentially independent, and that they are by different authors is not detrimental. These chapters, especially that dealing with waterproofing mechanisms in animals and plants, add greatly to the interest of the book, and Dr. Moilliet is to be congratulated on his decision to include them. 